\title{
Who watches Korean TV dramas in Africa? A preliminary study in Ghana
}

Media, Culture \& Society 2018, Vol. 40(2) 296-306

(C) The Author(s) 2017

Reprints and permissions: sagepub.co.uk/journalsPermissions.nav DOI: I0.II77/0I634437|7706069 journals.sagepub.com/home/mcs

\section{Suweon Kim}

University of the Western Cape, South Africa

\begin{abstract}
More and more Ghanaians are watching Korean TV dramas. These are not just ordinary Ghanaians because they are from a particular socioeconomic bracket; they have a certain level of education, access to screen devices and Internet, accumulated previous experience of watching other foreign screen products and, most importantly, a peer network with those who can afford these items. Drawing from qualitative work and focus-group interviews, the article argues that Korean TV dramas are spread efficiently by taking advantage of those contributing components within the privileged network, but they remain within the network due to the lack of those necessary components outside the bracket. The recipients find Korean media products attractive because they are fresh, funny, socially decent, different, yet close to them vis-à-vis Hollywood and Nollywood.
\end{abstract}

\section{Keywords}

Africa, foreign media, Ghana, Hallyu, Korea, media audience

\section{Introduction}

South Korean (hereafter referred to as Korea) TV dramas are growing in popularity in Ghana. Conventional explanations for the craze of Korean popular culture across Asia, which benefited from physical proximity, cultural affinities and the substantial size of diasporic communities, are not applicable to this case. It takes more than 20 hours by plane to go to Accra from Seoul. There was virtually no cultural exchange prior to the 1990s between the two countries, and a small number of Koreans (approximately 800) are residing in Ghana, which includes about 200 sailors. $^{1}$ The growing reception of

\section{Corresponding author:}

Suweon Kim, Department of Political Studies, University of the Western Cape, Private Bag XI7, Bellville 7535, South Africa.

Email: kimsuweon@gmail.com 
Korean screen products in Ghana where most of its 26 million population have an almost non-existent image of South Korea asks for alternative explanations. What is even more intriguing is that the audience which proactively chooses to watch Korean media products belongs to a particular socioeconomic community.

The craze of Korean popular culture outside Korea is called 'Hallyu'. In the early 1990s, Korean TV dramas (KTVDs) were first aired in Japan, China, Taiwan and Hong Kong. In 1998, the Chinese news media coined the term Hallyu (Korean wave) to describe the sudden craving for KTVDs in China. Soon thereafter, it diffused to related genre and industries such as K-pop (Korean popular music), movies, food, tourism, and language. Geographically, however, it was contained mainly in Asia up until the end of the 1990s. In the 2000s, however, the combination of government initiatives to promote Hallyu to boost its soft power and the advancement of Internet spread Korean screen products to Latin America, Middle East Asia and Africa. Along with the recent expansion, Hallyu research has been paying increasing attention to the new terrain. Hübinette (2012) documented the reception and consumption of Korean popular culture in Scandinavian Europe with a case study of Sweden. Otmazgin and Lyan (2013) researched K-pop consumers in Israel and Palestine, and Ko et al. (2014) examined Hallyu in Peru and Brazil.

Regarding Sub-Saharan Africa, it appears that no academic attempt has been made to understand the recent reception of Korean popular culture in the region. Even though there was an academic attempt to understand the growing popularity of Korean popular culture in North African countries such as Egypt and Tunisia (Han and Lee, 2008), this region is culturally, politically and economically under the influence of Arabs and is categorised as the 'Arab-North Africa' region. The void results from the combination of a number of socioeconomic reasons. First, Hallyu in Africa is a relatively new phenomenon compared to that in Asia. Also, even though a number of anecdotal cases of Hallyu in Africa were reported, the sheer size of fandom is still trivial. In 2015, the size of Hallyu exports reached US\$7.03 billion, out of which Asia is still accounting for the majority, while the revenue generated from Sub-Saharan Africa is too meagre to be accounted for (KOTRA/KOFICE, 2016). Even without Korean media products, SubSaharan Africa has been marginalised in media studies in general. This region, however, offers its own peculiarity in media phenomena (Gray, 2011). This article explores the particular historical and contemporary context of media political economy that brings about the seemingly strange phenomenon of reception of Korean media products in Ghana.

Given the complete absence of studies on Hallyu in the region, this article aims to draw preliminary findings on the reception of Korean popular culture in Ghana and, by extension, in Africa. The findings indicate that a small but potentially influential demographic of the educated youth in economically well-off urban households has been proactively watching KTVDs. In Asia, America and Europe, Hallyu is within the reach of youth in the middle class. In Africa, however, financial and infrastructural barriers contain the spread within a limited privileged demographic. To clearly understand the recipients of Korean screen products in Ghana, a caveat is necessary. Due to the limits of a single research article, the focus of this article is limited to understanding who the recipients are, and how and why they choose Korean screen products for entertainment. In addition, since the reception of Korean cultural products is limited mostly to TV dramas 
in Ghana, the term Hallyu in this article is interchangeably used with the popularity in KTVDs to refer to the fledgling but noticeable reception of Korean screen products in Ghana. Finally, the research used a series of semi-structured focus group interviews in 2016. The article does not claim that the participants in the focus group discussion represent the KTVD audience in Ghana nor is it the intention of the article. The focus group method, however, was used to gain an understanding of the reception of Korean media products in Ghana and formulate future research directions based on this preliminary research on the subject.

Participants have watched more than 10 KTVDs in the 2 years prior to the study, and proactively chose to watch KTVDs through various channels such as TV broadcasting, Internet streaming, downloading, CDs/DVDs and file swapping. They are of Ghanaian nationality and fall within the 14-24 age group, with the exception of a 46-year-old participant who is watching KTVDs with her daughters who belong to the 14-24 age group. The average discussion and interview took approximately an hour and a half. Although the participants were allowed to use a pseudonym to protect their privacy, none of them opted to do so; however, the article changed their names to protect their identity.

\section{Ghana as a cultural milieu}

The history of mass media in Ghana began with radio, which was first distributed in 1935 by the British colonial government. Later in 1965, the first president of independent Ghana inaugurated Ghana Television. Both colonial and postcolonial governments understood the effectiveness of mass media and films as a means to educate people and to create a unity on behalf of the Empire and the independent nation, respectively (Alhassan, 2006: 211-216). To serve the purpose, both governments kept mass media under the monopoly of the state until the privatisation of broadcasting in 1994. Compared to mass media, film making was relatively free, but making films which needed a big budget has never been active in African media production. Consequently, the Ghanaian movie industry was dominated by foreign films. Until the $1980 \mathrm{~s}$, less than $5 \%$ of films exhibited in Ghana were locally produced, most of which were cultural and educational documentaries made by a state-owned film company (Meyer, 1999: 97; Sey, 2011: 392).

In the late 1980s, however, Ghana saw 'the spectacular eruption of video films', which were shot on electromagnetic tape instead of expensive celluloid films (Haynes, 2007: 1). Video films ${ }^{2}$ were made with an ordinary VHS camera by self-trained producers who acted as script writers and directors with a shoestring budget. They needed to produce films as cheaply and quickly as possible, distribute and recoup the investment within 2 weeks before the pirated copies of the movie caught up, and move on to shoot another film. The tight budget also constrained the genre to family melodrama which cost less to shoot. This practice made 'African movies' or so-called 'Nollywood', the popular term for low-quality movies made in Nigeria and Ghana; however, the films with witchcraft, family melodrama and hardships of ordinary Ghanaians captured local viewers (Omoera, 2009: 193). On the other hand, the elites in Ghana tend to prefer foreign films while looking down on African films for their low-quality sound and picture and a contrived storyline (Meyer, 1999: 97-100). The elite contempt of African movies spawns a favourable environment for the reception of foreign screen products. 
The different pattern of consuming cultural products between elites and ordinary Ghanaians grows bigger in the framework of the urban-rural division. Distribution of radio and TV broadcasting was carried out with the priority being urban areas, which resulted in the media scene in Ghana being an 'intra-urban affair' (Alhassan, 2006: 216). This division still exists in regard to Internet connectivity. The Ghanaian government's current strategy is concentrated on connecting regional capitals, and the digital divide between urban and rural areas has been growing wider (Gyaase and Takyi, 2014: 62). As a result, whereas $12.7 \%$ of urban dwellers are using Internet, in rural areas, only $2.1 \%$ are using Internet (Ghana Statistical Service, 2012). In addition, broadband services in Ghana still 'remain a luxury item for many Ghanaians' (Alliance for Affordable Internet, 2014: 4). Even though Ghana has entered into the ranks of the middle-income countries with US\$1590 of gross national income per capita (2014), 49\% of Ghanaians are living on under US\$3.10 a day, and almost a quarter of its population suffers under the national poverty line (World Bank, 2016). The cost of a broadband connection is high, and personal devices such as laptops, computers and tablets are still out of the reach of a majority of the population in Ghana.

Nevertheless, Ghana is 'the leading African country' regarding improvement in Internet access (ITU, 2015: 79). Even though Ghana was one of a very few African countries connected to the Internet before 1990, until the mid-2000s Ghana had virtually no residential Internet broadband connections; however, the country made impressive progress between 2010 and 2015, and the number of Internet users has more than doubled; in addition, the share of households with a computer increased by more than $25 \%$ during the 5-year period (ITU, 2015). No other African country achieved this improvement. This accomplishment, in part, may be ascribed to the government strategy recognising 'information and communication technologies as the main engine for accelerated and sustainable economic and social development' (The Government of Ghana, 2003: 21).

In most cases, the youth is the most beneficial demographic group from the advancement of the information and communication technology (ICT). In this sense, in Ghana, where the median age is 20.6 years, the outstanding advancement of ICT should be beneficial to the largest portion of its population (UN Population Division, 2015). ${ }^{3}$ In reality, however, the ordinary youth in Ghana cannot afford access to ICT due to lack of Internet or devices that can connect thereto; thus, the benefit of the advancement of ICT in confined to a small bracket of the youth who are living in urban area with Internet infrastructure and whose household can afford Internet and devices which are still too pricey and out of reach to ordinary Ghanaians. This limited social demographic can be found in private or international (junior) high schools and privileged universities.

According to Adam et al. (2015), Ghanaian university students, who represent the limited demographic, predominantly prefer sedentary leisure activities such as listening to music, watching TV, chatting with friends, and playing computer games, which combined account for more than $70 \%$ of preferred leisure activities among university students. In a similar study, Yankholmes and Lin (2012) find the congruent tendency and argue that the preference for non-active leisure activities can be understood from the traditional perception of leisure activities which view such activities as laziness and wastefulness; therefore, the sedentary and non-active leisure activities of Ghanaian students help to avoid the negative perception. This sedentary leisure pattern is also conducive to receiving foreign screen products for their pastime. 
In conclusion, the combination of the elite's scorn for local media products, the improved ICT infrastructure which is accessible and affordable only by a small limited number of members of urban populations, and the sedentary leisure style of Ghanaian university students has produced a social environment conducive to receiving foreign media products. Based on this understanding of the macro media/social context in Ghana, what is following goes down to the micro analysis to understand who the bellwethers of KTVDs are and why they proactively watch and recommend KTVDs to the peers in their network.

\section{'It is cool'}

KTVDs were introduced in Africa in the early 2000s by the Korean government, which then was already fully cognisant of the effect of Hallyu to boost its soft power. The Korea Creative Content Agency (KOCCA) purchased the sales rights and provided KTVDs to a number of African countries without charge. Around 2004, the first KTVDs in Ghana, 'Phoenix' and 'Full House' were aired on TV3, which opened with Thai ownership after the privatisation of the broadcasting industry in 1994. ${ }^{4}$ Most of the interviewees in this study were first exposed to KTVD on TV3 around this time. Today, however, they are transformed to prosumers (proactive consumers); they proactively choose which Korean shows to watch, and the channel has been moved to the web. In this sense, Hallyu in Ghana has been following the similar pattern from TV to ICT as was witnessed in other regions, which was named as Hallyu 2.0 (Jin, 2014).

The reception of Korean screen products in Ghana, however, shows a number of distinctive dimensions. In Ghana, they have been received by a small privileged sociodemographic group, and the genre is predominantly limited to TV dramas. The differences originate from the socioeconomy of Ghana and by extension, Africa. Being able to watch KTVDs means the recipients have a certain level of education, access to screen devices and Internet, accumulated previous experience of watching other foreign screen products and, most importantly, a peer network with those who can afford these items. KTVDs' popularity spreads efficiently by taking advantage of those contributing components within the privileged network, but they remain within the network due to the lack of those necessary components outside the bracket.

The peer network is critical in the expansion of KTVDs in Ghana. The original KTVD peer networks are found in private or international (junior) high school and privileged universities. The peers in the school shape the network through which they exchange and obtain KTVDs. Princess, who is in junior high school, said half of her KTVDs were obtained from her friends as a soft copy and the other half from pirated CDs. She and her classmates purchase pirated CDs on the street and swap them among their peers. A CD with a complete series of one drama costs three cedis, equivalent to US\$0.80. For those who have started watching KTVDs relatively recently, even their first encounter is taking place through recommendations from peers and not from the traditional media. For instance, Araba, a final year student of an international high school, where tuition is three times as expensive as ordinary public schools, watched her first KTVD on video streaming. She explains how she got curious about KTVDs in the beginning:

When she (Araba's classmate) spoke about it (KTVD), her eyes were lit and she was laughing and she was remembering something she saw and it was so vivid. Okay, I wanted to find out what she is talking about because she was really crazy. 
The peer network is even more salient among university students. They obtain most KTVDs through downloading and exchanging with peers. There are 'hard-core downloaders' among them who are using a special Internet bundle such as 'free download between 12 a.m. to 3 a.m.' Once one student downloads a new KTVD and likes it, the drama is recommended and the file is transferred to peers around the downloader, and the process repeats. At the end, you may not find the downloader but, according to the interviewees, around 6 out of 10 female and 1 out of 10 male university students seem to have at least one KTVD in their laptop or storage device through the process of recommendation and file transfer among peers.

Receivers in peer networks at schools and universities become senders in their households. The peer network easily expands to a family network in Ghana due to familyviewing culture. When any family member gets a new $\mathrm{CD}$ or file, the whole family tends to watch it together. The family viewing seems distinctive in Africa where individualism is still less prevalent than in Europe and America, and increasingly in Asia. The limited number of screen devices in each household can contribute to the family viewing as well.

The culture of family viewing is conducive to choosing KTVDs whose storylines and graphics are perceived as socially conservative vis-à-vis Western and African screen products. Prior to KTVDs, most interviewees had long been exposed to the now-toofamiliar Western screen products and the violent and sensual Nigerian movies which buried the local screen industry. On the other hand, KTVDs are fresh and their contents are socially conservative. Yaa, a 43-year-old government official, watches KTVDs from files and CDs that her daughters bring home. She explains the reason she enjoys watching KTVDs as,

It is cool, decent, and the culture is very good for us. Korean movie is the movie I will recommend for my child. It is a movie that you are watching, your children are around, and you don't feel embarrassed.

The secondary viewer in the family who watched the KTVDs at home becomes a new sender to their own peer networks. Yaa became the epicentre in her workplace providing KTVD files to her colleagues; however, the inter-network transfer has limits and ends at certain groups with access to infrastructure and screen devices in Ghana where the chronic electricity supply shortfalls and outages bedevil the daily lives of ordinary Ghanaians, most of whom cannot afford backup generators and screen devices (Energy Commission, Ghana, 2015). These barriers predated today's file-transferring era. Up until 2000, there were only 13 TV receivers per every 1000 Ghanaians (Avle, 2011: 11). The inaccessibility has increased because the majority of the viewing of KTVDs is taking place outside TV. University students are freer from the affordability trap since even students who do not have personal devices have access to devices in places like libraries and computer labs on campus. The shift of media from TV to ICT devices is most salient to university students, most of whom stopped watching KTVDs on TV; they do not want to wait for the next episode or miss an episode when they can simply download and watch the same series on the Internet. At the time of interviewing, Joy Prime, one of the private broadcasting companies in Ghana, is showing a KTVD, 'You Are All Surrounded' every night in prime time between 9 p.m. and 10 p.m., but most university students were not even aware of it, while interviewees in (junior) high school were watching it on TV. 
Another decisive constraint to the wider expansion of KTVDs outside the limited demographic is the level of previous education. In Ghana, only $1.7 \%$ of the population has a bachelor's degree and almost a half of the population has no education $(23.4 \%)$ or primary education only (24.8\%) (Ghana Statistical Service, 2012). Even though some statistics say more than three quarters of Ghanaians over the age of 15 can read and write, this does not mean they are literate enough to read English subtitles to follow the story of foreign TV dramas (Central Intelligence Agency, 2016); rather, the significant portion of Ghana's population that is illiterate or semi-illiterate makes foreign dramas with English subtitles hard to follow. Even when they are dubbed in English, subtitles with the local language are needed since a lot of local people do not fully understand English and cannot read fast enough to follow the storyline. When people communally watch a foreign TV drama in a marketplace, usually someone who understands better narrates what happened in the previous episode in local dialect before the new episode starts. When a foreign drama becomes popular, an after-talk show is aired after the drama explaining what happened in detail in local dialect.

These communal viewers also watch KTVDs on TV in marketplaces, but they do not exactly choose to watch them. They watch them because they are on TV. More importantly, in most cases, the communal viewers are not aware that they are watching KTVDs. Instead, they call KTVDs Kung-fu movies, the name they give to all TV dramas featuring Asians. In this sense, it will be incorrect to refer them as KTVD recipients. On the other hand, the interviewees in this study were able to distinguish Korean from Chinese and Japanese by the sound and character of the Korean language and say a few sentences and words in Korean. ${ }^{5}$ They also did not like the idea of KTVDs dubbed in English or a local language, adding they 'love to listen to Hangul (Korean language)', and they would not feel it was real if it were dubbed.

University students are 'the highly "privileged" social group' in Ghana (Adam et al., 2015: 145). Hallyu has been spreading among university students and potential university students and their families. They find KTVDs comic, fun, delightful, lively and inspiring. For them, KTVDs are something different. They like to listen to the soft sound of the Korean language and watch different facial expressions, attitudes, foods, architecture, and traditional clothing. All of these are so different from their local culture and Anglo-speaking cultures which are too familiar to their eyes. The cultural dissimilarities attract viewers in Ghana, contrasting to Hallyu in Asia. Viewers also find the storylines intriguing and the acting realistic. In comparison to Hollywood TV dramas which are unrealistic when presented as comedy, and gloomy and heavy when presented as reality, participants found KTVDs funny and realistic. In contrast to African screen products imbued with daily hardships of ordinary Africans, with which most of the interviewees cannot sympathise easily, KTVDs are pleasant to their eyes displaying material opulence, various types of foods, colourful traditional dress, respectful attitudes and smooth modernity. In this sense, the recipients can be understood within the framework of the hybridity community. Harindaranath (2003) argues that the hybridity community - an economic, political, and cultural elite community in (former) Western colonies - interpret cultural products closer to audiences in the colonising country than to audiences without the experience of high education in their own country. However, the audience in this study is still different from the authentic hybridity community since their engagement with foreign cultural products cannot be understood as collaboration with global 
media capital for economic gains, and Korean media products are not exactly from the culture of Ghana's former colonisers. Nonetheless, it is noteworthy that the participants found comfort watching KTVDs, escaping from hardships of ordinary fellow Ghanaians by which they are surrounded but cannot exactly feel connected:

I once watched it (respondent's first KTVD) and I was really, really happy that day. ... It was funny. The way they spoke was funny, nice, and it was lively ... . I've written so much about threes, life, skies, poor people, sad people. I was always so concerned about reality and I was sad that poor people being ignored ... my writing focuses much on negative stuff ... And all of sudden, when I watch Korean dramas I got inspired again to rise more. ... there is somewhere I will be appreciated. (Araba)

\section{Concluding remarks}

Ghana is one of those African countries where KTVDs were first aired in the mid-2000s. The viewers who mostly encountered KTVDs on TV have turned to the ICT media to watch more KTVDs and proactively choose what they like to watch; however, due to the financial, educational, and infrastructural constraints, the viewing of KTVDs is confined to a limited demographic. Within the group, peer networks play a decisive role in introducing and delivering new KTVDs. While different age groups show different channels of reception, they are all based on peer networks such as recommendation, transferring or swapping files and co-watching. The financial capacity which allows them access to Internet data, screen or storage devices, and a certain level of education plays an imperative role within the network but, at the same time, the lack of it becomes the barrier to expanding Hallyu to ordinary Ghanaians. The study also found that the audience in Ghana finds KTVDs appealing because they are socially conservative, funny, different, yet close to them compared to the Hollywood or Nollywood screen products.

As a preliminary research on the reception of Korean screen products in Africa, this study raises a few questions that may prompt further research. This study made an attempt to understand the recipients of Hallyu in Africa using the case of Ghana. The popularity of Korean media products among university students seems to be found in other parts of Africa; Gray's (2011: 107) ethnographic research on Malawi's video markets suggests that only in the university town of Zomba, did he find Korean films but not in stalls and stores in other towns. Still, a number of Ghanaian factors should be taken into consideration. Ghana has the best education system in West Africa, and Ghanaians are known for their passion for education. In addition, the Ghanaian government has been emphasising the role of ICT in economic development and, compared to other African countries, making outstanding progress in the field, which played a critical role in increasing the popularity of KTVDs in Ghana. In this sense, to understand Hallyu in other parts of Africa, based on the findings of this study, a nation-specific analysis needs to be added.

In addition, the size of Hallyu in Ghana and in Africa needs to be researched for systemic analysis. Even though measuring the size of them was beyond the limit of this study as a single preliminary research, it is estimated that there is significant number in a university setting. Kojo's anecdote is worth quoting to understand the size: 
(In 2013,) I (university student) had a presentation in class for my second year. We had to do some research on perception. We were psychology students and we talked about beauty is in the eyes of the beholder. We showed different pictures of different people and asked people in the class 'do you think they are beautiful'. When we popped out his (Lee Minho, an actor in Korean TV dramas) picture, the whole class went upside down.

Another interesting dimension of the proactive reception of Korean media products in Ghana which the study could not delve into is that the reception is limited to Korean media products (and traditionally Bollywood) but not the cultural products from the more influential players in Asia such as China and Japan, despite their active engagement with Africa on all fronts. The participants tend to connect Japanese screen products with their parent's generation and showed a nuanced scorn of Chinese media product. Out of all of the Asian alternatives to the West, given that Chinese illegal gold mining in Ghana frequently gains negative reporting in Ghanaian news media, Korean media products could be perceived as what Iwabuchi (2002) calls historically, culturally and politically 'odourless' to Ghanaians.

In addition, further research is needed on the polarisation of media consumption in Ghana and, by extension, Africa, particularly regarding the reception of foreign media. In a similar research on the reception of foreign media products in Sub-Saharan Africa, Gray (2014) interviewed video show goers in Malawi. Even though ordinary Ghanaians do go to video shows, they almost do not overlap with recipients of KTVDs in this article. The polarisation is more noteworthy from the aspect of the youth bulge in the region. Despite the hype of Africa being the youngest continent and the youth being the most active demographic group in receiving foreign screen products and the ICT, the study suggested that the low purchasing power and the lack of infrastructure exclude the ordinary youth in Africa from the reception of particular foreign culture on which further research should focus.

\section{Funding}

The author(s) received no financial support for the research, authorship, and/or publication of this article.

\section{Notes}

1. These statistics from 2014 provided by the Korean embassy in Ghana.

2. Meyer (1999: 98) argues that the video boom came 'out of people's desire to see their own culture mediated through a television or cinema screen'. Meyer's argument, though correct, seems to place over-emphasis on postcolonial reasons for the boom. Economic reasons were equally compelling, and according to Haynes (2007: 1), Nigeria's increasing crime rate was another cause of the boom which made people avoid going out to watch movies and, instead, stay home watching video films.

3. The median age in Europe is 42 years (UN Population Division, 2015).

4. TV 3 is currently the second-most-watched TV station in Ghana with an audience share of $20.7 \%$ and has been broadcasting foreign TV dramas, including India TV series, telenovelas and KTVDs (Ghana News, 2015). The ownership of TV3 later moved to a Malaysian company and currently it is under Ghanaian ownership. 
5. Almost all interviewees, on the other hand, said they cannot distinguish Chinese from Japanese.

\section{References}

Adam I, Hiamey SE and Afenyo EA (2015) Leisure constraints in the university setting in Ghana. Annals of Leisure Research 18(1): 145-158.

Alhassan A (2006) Market valorization in broadcasting policy in Ghana: abandoning the quest for media democratization. Media, Culture \& Society 27(2): 211-228.

Alliance for Affordable Internet (2014) Affordable internet in Ghana: the status quo and the path ahead, 26 March. Available at: http://a4ai.org/wp-content/uploads/2014/03/Ghana-CaseStudy-Layout-Final.pdf (accessed 26 March 2016).

Avle S (2011) Global flows, media and developing democracies: the Ghanaian case. Journal of African Media Studies 3(1): 7-23.

Central Intelligence Agency (2016) The World Factbook: Ghana, 11 July. Available at: https:// www.cia.gov/library/publications/the-world-factbook/geos/gh.html (accessed 22 July 2016).

Energy Commission Ghana (2015) 2015 energy (supply and demand) outlook for Ghana, April. Available at: http://energycom.gov.gh/files/Energy\%20Outlook\%20for\%20Ghana\%20-\%20 2015.pdf (accessed 28 April 2016).

Ghana News (2015) UTV most watched TV station in Ghana - Report, 1 December. Available at: http://citifmonline.com/2015/12/01/utv-most-watched-tv-station-in-ghana-report/ (accessed 21 March 2016).

Ghana Statistical Service (2012) 2010 population and housing census: summary report of final results, May. Available at: http://www.statsghana.gov.gh/docfiles/2010phc/Census2010 Summary_report_of_final_results.pdf (accessed 26 March 2016).

Gray J (2011) Mobility through piracy, or how Steven Seagal got to Malawi. Popular Communication 9(2): 99-113.

Gray J (2014) Scales of cultural influence: Malawian consumption of foreign media. Media, Culture \& Society 36(7): 982-997.

Gyaase PO and Takyi A (2014) A case for public financing of broadband internet infrastructure in Ghana. International Journal of Scientific \& Technology Research 3(2): 60-68.

Han H and Lee J (2008) A study on the KBS TV drama Winter Sonata and its impact on Korea's Hallyu tourism development. Journal of Travel \& Tourism Marketing 24(2-3): 115-126.

Harindaranath R (2003) Reviving 'cultural imperialism': international audiences, global capitalism, and the transnational elite. In: Parks L and Kumar S (eds) Planet TV: A Global Television Reader. New York: New York University Press, pp. 155-168.

Haynes J (2007) Video boom: Nigeria and Ghana. Postcolonial Text 3(2): 1-10.

Hübinette T (2012) The reception and consumption of Hallyu in Sweden: Preliminary findings and reflections. Korea Observer 43(3): 503-525.

ITU (2015) International Telecommunication Union: measuring the Information Society Report 2015. Available at: http://data.worldbank.org/indicator/SI.POV.2DAY (accessed 26 March 2016).

Iwabuchi K (2002) Recentering Globalization: Popular Culture and Japanese Transnationalism. Durham, NC: Duke University Press.

Jin DY (2014) The power of the nation-state amid neo-liberal reform: shifting cultural politics in the new Korean Wave. Pacific Affairs 87(1): 71-92.

Ko NC, No S, Kim JN and Simões RG (2014) Landing of the wave: Hallyu in Peru and Brazil. Development and Society 43(2): 297-350.

KOTRA/KOFICE (2016) [Research on the Economic Impact of Hallyu]. Seoul: KOTRA/Korea Foundation for International Culture Exchange. 
Meyer B (1999) Popular Ghanaian cinema and 'African Heritage'. Africa Today 46(2): 93-114.

Omoera OS (2009) Video film and African social reality: A consideration of Nigeria-Ghana block of West Africa. Journal of Human Ecology 25(3): 193-199.

Otmazgin N and Lyan I (2013) Hallyu across the desert: K-pop fandom in Israel and Palestine. East Asian History and Culture Review 9(December): 68-99.

Sey A (2011) New media practices in Ghana. International Journal of Communication 5(2011): $380-405$.

The Government of Ghana (2003) The Ghana ICT for Accelerated Development (ICT4AD) Policy. Accra: The Government of Ghana.

UN Population Division (2015) World Population Prospects: The 2015 Revision, Key Findings and Advance. New York: The United Nations.

World Bank (2016) Poverty headcount ratio at \$3.10 a day (2011 PPP) (\% of population). 17 February. Available at: http://data.worldbank.org/indicator/SI.POV.2DAY (accessed 26 March 2016).

Yankholmes AKB and Lin S (2012) Leisure and education in Ghana: an exploratory study of university students' leisure lifestyles. World Leisure Journal 54(1): 58-68. 